\title{
Atomic Force Microscopy Provides New Mechanistic Insights into the Pathogenesis of Pemphigus
}

\author{
Franziska Vielmuth, Volker Spindler and Jens Waschke* \\ Institute of Anatomy, Faculty of Medicine, Ludwig-Maximilians-Universität München, Munich, Germany
}

Autoantibodies binding to the extracellular domains of desmoglein (Dsg) 3 and 1 are critical in the pathogenesis of pemphigus by mechanisms leading to impaired function of desmosomes and blister formation in the epidermis and mucous membranes. Desmosomes are highly organized protein complexes which provide strong intercellular adhesion. Desmosomal cadherins such as Dsgs, proteins of the cadherin superfamily which interact via their extracellular domains in $\mathrm{Ca}^{2+}$-dependent manner, are the transmembrane adhesion molecules clustered within desmosomes. Investigations on

OPEN ACCESS

Edited by:

Ralf J. Ludwig,

University of Lübeck, Germany

Reviewed by:

Etienne Dague,

Centre national de la recherche scientifique (CNRS), France

Peter König,

University of Lübeck, Germany

${ }^{*}$ Correspondence: Jens Waschke jens.waschke@med. unimuenchen.de

Specialty section: This article was submitted to Immunological Tolerance and Regulation,

a section of the journal Frontiers in Immunology

Received: 21 December 2017 Accepted: 23 February 2018 Published: 28 March 2018

Citation:

Vielmuth F, Spindler $V$ and Waschke J

(2018) Atomic Force Microscopy

Provides New Mechanistic Insights into the Pathogenesis of Pemphigus.

Front. Immunol. 9:485.

doi: 10.3389/fimmu.2018.00485 pemphigus cover a wide range of experimental approaches including biophysical methods. Especially atomic force microscopy (AFM) has recently been applied increasingly because it allows the analysis of native materials such as cultured cells and tissues under near-physiological conditions. AFM provides information about the mechanical properties of the sample together with detailed interaction analyses of adhesion molecules. With AFM, it was recently demonstrated that autoantibodies directly inhibit Dsg interactions on the surface of living keratinocytes, a phenomenon which has long been considered the main mechanism causing loss of cell cohesion in pemphigus. In addition, AFM allows to study how signaling pathways altered in pemphigus control binding properties of Dsgs. More general, AFM and other biophysical studies recently revealed the importance of keratin filaments for regulation of Dsg binding and keratinocyte mechanical properties. In this mini-review, we reevaluate AFM studies in pemphigus and keratinocyte research, recapitulate what is known about the interaction mechanisms of desmosomal cadherins and discuss the advantages and limitations of AFM in these regards.

Keywords: atomic force microscopy, desmosome, pemphigus, desmosomal cadherin, cell adhesion

\section{INTRODUCTION}

Pemphigus with the two main forms pemphigus vulgaris (PV) and pemphigus foliaceus (PF) represents a group of autoimmune blistering skin diseases in which autoantibodies develop primarily against the desmosomal cadherins desmoglein (Dsg) 1 and 3. This leads to weakened keratinocyte cohesion by a vast and yet only partially understood set of mechanisms and in consequence causes intraepidermal splitting $(1,2)$. Patients suffer from painful blistering affecting skin and mucous membranes, including the risk of infections and nutritive problems $(3,4)$. A broad range of methods, including functional adhesion assays, molecular biology, and immunological approaches as well as animal models are used study pemphigus pathogenesis $(2,5)$. The investigation of some mechanisms underlying desmosome dysfunction, e.g., impaired desmosome turnover, requires complex 
model systems such as passive IgG transfer in mouse models or ultrastructural analysis of human skin ex vivo (6). However, reductionist approaches such as atomic force microscopy (AFM) analysis of Dsg-binding properties and distribution either in cell-free models or 2D keratinocyte cultures yield important information about the effects of autoantibodies on the function of cell adhesion molecules. Moreover, these effects can be analyzed in concert with morphological alterations typical for pemphigus such as keratin filament retraction and changes in overall mechanical properties of keratinocytes. Insights in the mechanisms of desmosomal cadherin interactions and their regulation by intracellular signaling and plaque proteins may provide the molecular basis for targeted therapies in pemphigus. In the following, we will summarize the conclusions that could be drawn from studies utilizing AFM force spectroscopy and elasticity mapping to investigate pemphigus pathogenesis and outline strengths and weaknesses of this experimental approach.

\section{PRINCIPLE OF CELL-FREE AND CELL SURFACE AFM MEASUREMENTS}

Atomic force microscopy is used to construct topography maps based on the deflections of a flexible cantilever equipped with a sharp detection tip. Driven by highly accurate piezo steppers, the tip scans a freely definable region of interest while deflection of the cantilever is detected by the displacement of a laser beam on a photodiode (Figure 1A). This setup allows the measurement of virtually all kinds of materials. Being a non-optical imaging technique, the resolution is not limited by diffraction of light and reaches a spatial resolution down to $0.5-1 \mathrm{~nm}$ (7). Important for the field of basic biology, living cells, e.g., keratinocytes, can be imaged under near-physiological conditions $\left(37^{\circ} \mathrm{C}\right.$, medium) without the necessity of fixation $(8,9)$. Depending on the imaging mode, mechanical properties such as elasticity of the sample can be acquired together with information about the surface topography $(10,11)$ (Figure 1B). The combination of AFM topography and elasticity mapping with force spectroscopy provides an additional set of data that can be extracted from the same scan (Figure 1B). In this approach, recombinant adhesion molecules, e.g., the extracellular domains of desmosomal cadherins, are coupled to the AFM tip (Figures 1C,D). The tip is repetitively lowered to and retracted from a given surface, e.g., a cell membrane. Scanning with these functionalized tips provides information about the binding partners of the respective molecule, their localization (e.g., position in the membrane) (Figure 1B), and a set of biophysical properties of single-molecule interactions, such as binding forces, lifetimes of the respective bonds, and step position $(12,13)$.

Several methods are established for protein functionalization of AFM cantilevers (14). However, usage of heterobifunctional PEG-linkers is often preferred because it allows coupling of the molecule of interest to the distal end of the linker and ensures a reproducible detection radius throughout the experiments (15). In addition, these linkers allow coupling with a broad range of molecules through amino groups (15). Thus, it is possible to coat full-length extracellular domains of desmosomal cadherins which has been done with his-tagged monomers (Figure 1C) (16) as well as with Fc-tagged dimers (Figure 1D) (17). The second setup was applied based on experiments using classical cadherins, in which cis-dimerization was thought to be crucial for proper adhesive function $(18,19)$. However, both approaches showed specific homophilic and heterophilic binding events (16, 20-22). Due to the freely moving linkers, the achievable resolution is reduced to around $50 \mathrm{~nm}$ (14) which is suitable for capturing desmosomal cadherin clusters at the surface of living keratinocytes. Importantly, AFM force spectroscopy can be combined with other imaging modalities. These range from conventional and superresolution fluorescence microscopy techniques to electron microscopy and may help to overcome technical limitations, such as non-specificity of adhesion measurements and low imaging speed $(23,24)$. Together, this highly flexible AFM-based multimodal imaging allows the simultaneous acquisition of a wide range of different parameters.

For characterization of binding properties of desmosomal cadherins often cell-free approaches are used in which recombinant proteins are immobilized not only on the scanning tip but also on the surface of, e.g., a silicon nitrite mica-sheet (25). This reductionist model allows unequivocal evaluation of binding partners and forces because the possible interaction partners are clearly defined (Figure 1E). By contrast, keratinocytes express several isoforms of desmosomal cadherins (Figure 1F) which hinders a clear identification of interaction partners. Moreover, cell monolayers are more complicated to handle because of the necessity of measurements under near-physiological conditions, including temperature control and application of media to avoid starving (8). The continuous reorganization and morphological changes of the monolayer limit lateral resolution and are challenging because of the time necessary for AFM measurements (14). On the other side, the increased complexity by application of living cells has numerous advantages and adds novel possibilities to characterize desmosomal adhesion. Changes of cell topography and mechanical properties can be monitored in response to manipulation of signaling pathways or genetic depletion of specific proteins (26-28). In addition, alterations in the localization of Dsg clusters at the surface of living keratinocytes, their mobility $(20,29)$, and the binding properties can be elucidated $(20,30)$. Vice versa, changes in cell behavior or intracellular signaling activity can be detected following AFM-based manipulation such as indentation of the membrane or severing of cytoskeletal components $(31,32)$.

\section{AFM TO ELUCIDATE Dsg-BINDING PARTNERS AND TO STUDY THE EFFECTS OF AUTOANTIBODIES}

Desmogleins and desmocollins have been shown to bind both in homophilic- and heterophilic fashion under cell-free conditions $(17,33,34)$. By cell-free single-molecule AFM force spectroscopy using recombinant Fc-dimers of the entire extracellular domain, we found that Dsg1, Dsg2, Dsg3, and Dsc3 can interact homophilically. Importantly, these homophilic interactions were blocked by both EGTA treatment as 

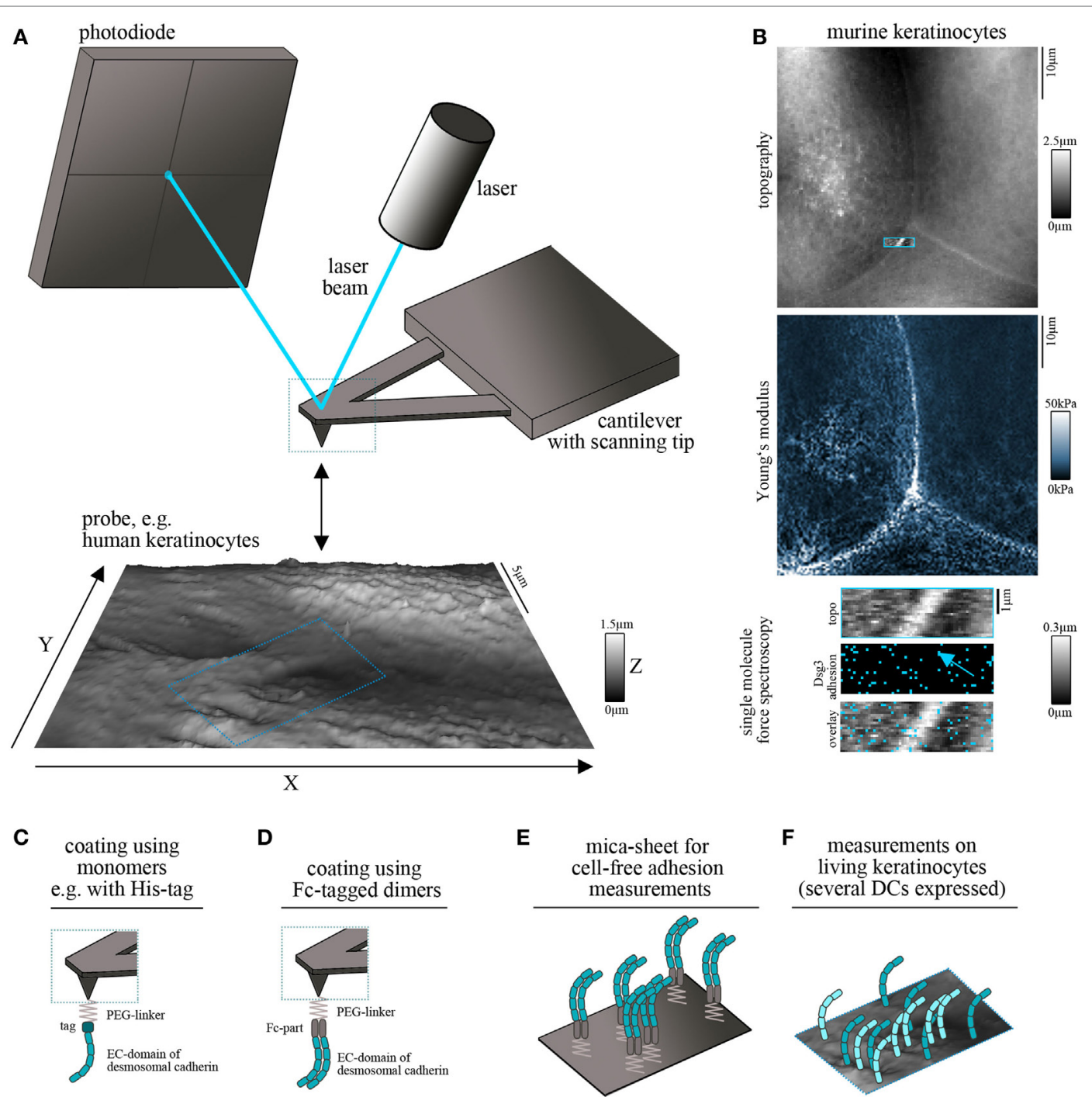
F measurements on living keratinocytes (several DCs expressed)

FIGURE 1 | Atomic force microscopy (AFM) setup for cadherin binding studies. (A) Schematic of an AFM setup. A flexible cantilever equipped with a sharp tip is repetitively lowered to and retracted from the surface of the probe. Deflection of the cantilever while contacting the surface is detected by a laser pointed on the cantilever and provides information about surface topography and mechanical properties. (B) Example for simultaneous measurement of topography (with elevated cell borders and filamental structures on the cell surface), elasticity (Young's modulus) and Dsg3 adhesion map (with each blue pixel represents on Dsg3-dependent binding event, arrow points on the cell border) on living murine keratinocytes. (C,D) To study single-molecule interaction tips can be functionalized with recombinant adhesion molecules using PEG-linkers. For desmosomal cadherins coating was conducted using full-length extracellular domains as either monomers

(C) or FC-tagged dimers (D). (E) Probe setup for cell-free measurements on mica sheets coated with Fc-tagged dimers of desmosomal cadherin extracellular domains. (F) Probe setup for measurements on living keratinocytes. Cells express several desmosomal cadherin isoforms on their cell surface.

well as incubation with specific antibodies (16, 20, 21, 35, 36). As another indication for specific homophilic interactions, the bond rupture forces increased with the applied loading rate similar to classical cadherins (18, 37-39). Corresponding lifetimes were delineated at $\tau_{0} \approx 0.17$ for Dsg1, $\tau_{0} \approx 0.31$ for Dsg3, and $\tau_{0} \approx 0.24 \mathrm{~s}$ for Dsc3 in cell-free AFM experiments and $\tau_{0} \approx 0.31$ for Dsg3-dependent binding events on murine keratinocytes $(20,29,35,36)$ which were significantly lower than detected for classical cadherins $(18,37)$. Homophilic interactions of Dsc2 but not Dsg2 monomers were also observed recently (16). With regard to heterophilic interactions, binding of Dsg2 to Dsc2 and Dsg3 was observed by AFM as well as interactions between Dsg1 and Dsc3 (16, 20, 35). In a systematic approach, only heterophilic interactions of Dsgs and desmocollins were found by surface plasmon resonance measurements although homophilic interactions were observed when high concentrations of molecules were applied, which allowed to determine the crystal structure of two interacting Dsg2 molecules (40). The reasons for these in part contradictory in vitro findings are unclear yet. Nevertheless, in living keratinocytes, homophilic interactions appear to be a primary mode of interaction as revealed by extracellular cross-linking (41). In line with this, we detected primarily homophilic interactions of Dsg3 on the surface of living keratinocytes $(20,29)$. 
Atomic force microscopy was further used to study the effects of pemphigus autoantibodies on Dsg binding. To be pathogenic and result in loss of cell cohesion, autoantibodies would either need to block Dsg interactions or lead to reorganization and internalization of Dsg molecules (Figure 2A). In the first concept, autoantibodies may sterically hinder interaction by preferentially targeting the adhesive EC1 domain of Dsgs or allosterically lead to conformational changes of the adhesive interface. These modes of interactions may be summarized as direct inhibition (Figure 2A). Release of Dsgs from desmosomes

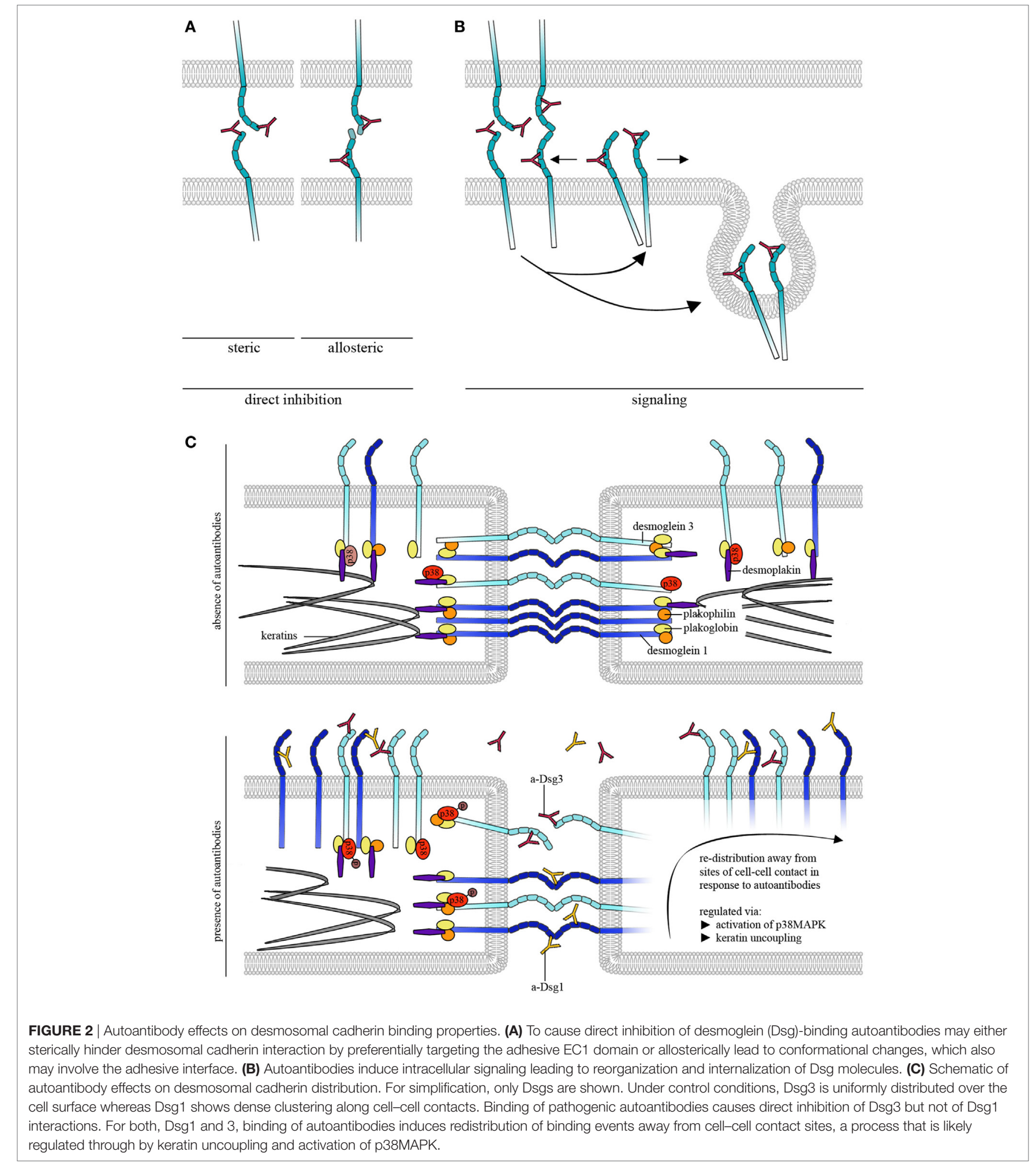


and endocytosis would require additional cellular mechanisms and intracellular signaling (Figure 2B). For instance, it is possible that extradesmosomal molecules serve as scaffolds which, dependent on autoantibody binding modulate signaling pathways and, thus, influence the composition and turnover of desmosomes. We sought to apply pemphigus autoantibodies in cell-free AFM in order to demonstrate direct inhibition of Dsg binding which represented the most likely mechanism of antibody action (42). However, we were surprised that PF-IgG did not directly interfere with Dsg1 binding (17). Meanwhile, using various IgG fractions of both PF-IgG and PV-IgG, we were not able to detect direct inhibition of Dsg1 interaction, both in cellfree and in cell-based measurements $(34,43,44)$. By contrast, in all experiments using PV-IgG or the monoclonal Dsg3-specific antibody AK23 derived from a pemphigus mouse model (45) direct inhibition of Dsg3 binding was demonstrated (26, 34, 43, $44,46)$. Thus, these data do not rule out that some autoantibodies targeting Dsg1 may occur which also cause steric hindrance, especially since some antibodies isolated from patients by phage display have been shown to interact with both Dsg1 and Dsg3 (47). However, the amount of these appears to be low if present in IgG fractions of many patients.

Atomic force microscopy studies also showed that a Dsgspecific tandem peptide designed to cross-link interacting Dsgs was effective to abrogate PV-IgG- and AK23-induced loss of keratinocyte cohesion in culture and in living mice indicating that direct inhibition of Dsg3 binding contributes to blister formation $(46,48)$. However, since the peptide approach also abolished activation of pathogenic signaling pathways such as $\mathrm{p} 38 \mathrm{MAPK}$ and pharmacologic inhibition of p38MAPK was effective to override autoantibody-induced loss of cell adhesion in the presence of autoantibodies directly inhibiting Dsg3 interaction, steric hindrance alone appears not to be sufficient to cause full loss of keratinocyte cohesion $(26,48)$. It has to be noted that a limitation of AFM interaction studies is that recombinant Dsg molecules attached to the AFM probe primarily will interact with extradesmosomal Dsg rather than Dsg1 and 3 in the core of desmosomes. This means that AFM studies cannot definitely prove that PV-IgG and AK23 are directly inhibiting the interaction of Dsg3 molecules inside of desmosomes. Nevertheless, because it was shown by immune-electron microscopy that the IgG-variant but not the IgM-variant of AK23 accessed the desmosomal core (49), it is likely that direct inhibition of Dsg3 binding in pemphigus also occurs in desmosomes and thereby contributes to desmosome dysfunction (6).

\section{AFM TO QUANTIFY ALTERATIONS OF KERATINOCYTE ELASTICITY AND CYTOSKELETAL REORGANIZATION IN RESPONSE TO AUTOANTIBODIES}

The cytoskeleton of eukaryotic cells comprises actin filaments, intermediate filaments, and microtubules. Keratin filaments, the intermediate filaments in cells of epithelial origin anchoring desmosomes, are pronouncedly affected in pemphigus. The so called "keratin retraction" describes the uncoupling of keratin filaments from desmosomes and the clustering around the nucleus. By AFM, keratin filaments can be visualized as stiff bundles underneath the membrane in the cell periphery inserting perpendicular to areas of cell-cell contact into desmosomes $(26,28)$. Interestingly, changes in the peripheral keratin network occur very rapidly within $1 \mathrm{~h}$ after autoantibody incubation and appear to even precede Dsg3 endocytosis, another hallmark of pemphigus $(26,50)$. Here, the first visible alteration is a reduced amount of keratin filaments in the basal part of the cell near areas of cell-cell contact, a region implicated in assembly of keratin filaments (51). ${ }^{1}$ Furthermore, as demonstrated by AFM elasticity mapping and optical stretching, keratin filaments in contrast to the actin cytoskeleton are the main constituents responsible for keratinocyte stiffness (52-54). In line with these data and the observations that keratin filaments are rapidly altered upon application or pemphigus autoantibodies, elasticity changes in response to autoantibody binding were described (31). By probing the membrane above the nucleus, a rapid reduction in cellular stiffness was observed within minutes followed by an increase after several hours, the latter of which may be a result of keratin clustering around the nucleus. Nevertheless, it is unclear whether these changes are mainly a result of keratin reorganization or whether other mechanisms contribute, as these changes were related to FasL-dependent apoptotic signaling (31).

The actin cytoskeleton is also severely altered by autoantibody binding $(55,56)$. Strengthening of the cortical actin meshwork prevented autoantibody-induced loss of cell cohesion in keratinocytes, indicating a contribution of actin reorganization to epidermal blistering (57). In principle, the actin meshwork underneath the membrane is accessible for AFM-based imaging (58-60), albeit with reduced resolution compared to approaches involving a membrane "deroofing" step or insideout measurements of membrane patches $(61,62)$. By AFM, the differentiation between the cortical actin and other cytoskeletal components is barely possible, especially because a cortical keratin filament meshwork may exist (63). Nevertheless, the observation that the delicate mesh pattern of the membrane of murine keratinocytes appears similar in cells with and without expression of keratin filaments indicates that these structures represent the cortical actin cytoskeleton (20). If and in which timeframe specific changes of the cortical actin cytoskeleton can be detected by AFM imaging remains to be elucidated.

\section{STUDIES ON Dsg DISTRIBUTION PATTERNS AND BINDING PROPERTIES MODULATED BY PEMPHIGUS ANTIBODIES}

In keratinocytes, Dsg3 and 1 are differentiation-dependently localized at sites of cell-cell junctions $(64,65)$. Interestingly, AFM

${ }^{1}$ Schlögl E, Radeva M, Vielmuth F, Schinner C, Waschke J, Spindler V. (under review). Keratin retraction and Dsg3 internalization independently contribute to autoantibody-induced cell dissociation in pemphigus vulgaris. Submitted to Immunology. 
measurements showed that Dsg3 binding events are uniformly distributed on the surface of living keratinocytes (29) (Figure 2C). This could be related to Dsg3 molecules that are detectable away from junctions and referred to as extradesmosomal (30, 66, 67). Thus, molecules detected close to cell-cell junctions may be extradesmosomal, located in desmosomal precursors or located at the edge of the desmosomal core, as the "center" of the tightly packed desmosomes is most likely not accessible for the AFM scanning tip. Nevertheless, these molecules differ with regard to their binding properties. Molecules at cell-cell junctions reveal higher binding forces compared to molecules on the cell surface above the nucleus (29). By contrast, Dsg1 binding events are not distributed uniformly but rather show higher binding frequencies along cell-cell junctions, indicating that clustering of Dsgs differs between isoforms (44, Figure 2C). In this context, keratins not only regulate cell mechanics $(53,54)$ but also differentially regulate Dsg-binding properties. For example, keratins are crucial for maintenance of Dsg3 binding strength as well as for distribution of Dsg1 at cell junctions $(20,44)$.

Binding of pemphigus autoantibodies to the extracellular domains of Dsg1 and 3 on the surface of living keratinocytes was shown to induce altered clustering of the targeted molecules (68-70). Using AFM, redistribution of Dsg1 binding events away from cell junctions occurred after treatment with pemphigus IgG fractions containing a-Dsg1 antibodies which may explain the structural changes described above (44). Dsg1 redistribution seems to be dependent on uncoupling from the keratin filaments which is a common phenomenon after treatment with pathogenic autoantibodies and precedes reduction of Dsg1 binding strength (Figure 2C) $(44,48,55)$. Due to direct inhibition of Dsg3 interaction, redistribution of Dsg3 molecules could not be evaluated after autoantibody treatment $(26,34)$. However, modulation of signaling pathways such as p38MAPK was used to mimic some effects of pemphigus autoantibodies on Dsg3 binding properties. p38MAPK is a central signaling molecule in pemphigus which is activated by binding of autoantibodies and was demonstrated to form a signaling complex containing Dsg3 and Dsc3 (71). Furthermore, activation of p38MAPK has been linked to keratin retraction and Dsg internalization whereas inhibition of p38MAPK prevented loss of intercellular adhesion (Figure 2C) (55, 66, 71-73). Interestingly, activation of p38MAPK led to keratin retraction and redistribution of Dsg 1 and 3 binding events away from junctions indicating that $\mathrm{p} 38 \mathrm{MAPK}$ signaling participates in the regulation of

\section{REFERENCES}

1. Kasperkiewicz M, Ellebrecht CT, Takahashi H, Yamagami J, Zillikens D, Payne AS, et al. Pemphigus. Nat Rev Dis Primers (2017) 3:17026. doi:10.1038/ nrdp.2017.26

2. Spindler V, Eming R, Schmidt E, Amagai M, Grando S, Jonkman MF, et al. Mechanisms causing loss of keratinocyte cohesion in pemphigus. J Invest Dermatol (2018) 138(1):32-37. doi:10.1016/j.jid.2017.06.022

3. Kneisel A, Hertl M. Autoimmune Bullous skin diseases. Part 2: diagnosis and therapy. JDtsch Dermatol Ges (2011) 9(11):927-47. doi:10.1111/j.1610-0387.2011.07809.x

4. Kneisel A, Hertl M. Autoimmune Bullous skin diseases. Part 1: clinical manifestations. JDtsch Dermatol Ges (2011) 9(10):844-56; quiz 57. doi:10.1111/j.1610-0387.2011.07793.x
Dsg clustering (Figure 2C) (44). Furthermore, inhibition of p38MAPK prevented autoantibody-induced redistribution of Dsg1 binding events and restored Dsg3 binding strength under conditions where keratinocytes were depleted from keratins $(20,44)$ indicating that Dsg-binding properties are strongly dependent on p38MAPK. Taken together, AFM adds important information on molecule distribution and binding properties of Dsgs after autoantibody incubation.

\section{CONCLUSION}

Atomic force microscopy complements a broad range of methods in pemphigus research. Under cell-free conditions, AFM enables characterization of single-molecule desmocadherin interactions with and without the presence of pemphigus autoantibodies. When applied on living keratinocytes, this can be complemented by monitoring cytoskeletal alterations. So far, AFM is the only technique with which direct inhibition of Dsg interactions by pemphigus autoantibody binding was detected on the singlemolecule level. Furthermore, it provides insights into alterations of keratinocyte properties. Although interaction partners on living cells cannot be completely identified and temporal resolution is low compared to other live-cell imaging approaches, investigation of Dsg mobility and redistribution in response to autoantibodies may add important information about the underlying mechanisms of loss of cell cohesion in pemphigus. Similarly, combination of Bio-AFM with high-resolution imaging techniques such as STED microscopy may elucidate whether alterations of Dsg binding properties in response to autoantibody binding maybe mediated by different association with signaling molecules and plaque proteins.

\section{AUTHOR CONTRIBUTIONS}

FV, VS, and JW designed the review, evaluated the literature, and wrote the manuscript.

\section{ACKNOWLEDGMENTS}

We thank the members of our group for fruitful discussion.

\section{FUNDING}

Supported by DFG FOR 2497 to JW.

5. Pollmann R, Eming R. Research techniques made simple: mouse models of autoimmune blistering diseases. J Invest Dermatol (2017) 137(1):e1-6. doi:10.1016/j.jid.2016.11.003

6. Spindler V, Waschke J. Pemphigus - a disease of desmosome dysfunction caused by multiple mechanisms. Front Immunol (2018) 9:136. doi:10.3389/ fimmu.2018.00136

7. Li M, Dang D, Xi N, Wang Y, Liu L. Nanoscale imaging and force probing of biomolecular systems using atomic force microscopy: from single molecules to living cells. Nanoscale (2017) 9(45):17643-66. doi:10.1039/c7nr07023c

8. Allison DP, Mortensen NP, Sullivan CJ, Doktycz MJ. Atomic force microscopy of biological samples. Wiley Interdiscip Rev Nanomed Nanobiotechnol (2010) 2(6):618-34. doi:10.1002/wnan.104

9. Parot P, Dufrene YF, Hinterdorfer P, Le Grimellec C, Navajas D, Pellequer JL, et al. Past, present and future of atomic force microscopy in life 
sciences and medicine. J Mol Recognit (2007) 20(6):418-31. doi:10.1002/ jmr.857

10. Alonso JL, Goldmann WH. Feeling the forces: atomic force microscopy in cell biology. Life Sci (2003) 72(23):2553-60. doi:10.1016/S0024-3205(03)00165-6

11. Zlatanova J, Lindsay SM, Leuba SH. Single molecule force spectroscopy in biology using the atomic force microscope. Prog Biophys Mol Biol (2000) 74(1-2):37-61. doi:10.1016/S0079-6107(00)00014-6

12. Muller DJ, Sapra KT, Scheuring S, Kedrov A, Frederix PL, Fotiadis D, et al. Single-molecule studies of membrane proteins. Curr Opin Struct Biol (2006) 16(4):489-95. doi:10.1016/j.sbi.2006.06.001

13. Sariisik E, Popov C, Muller JP, Docheva D, Clausen-Schaumann H, Benoit M. Decoding cytoskeleton-anchored and non-anchored receptors from singlecell adhesion force data. Biophys J (2015) 109(7):1330-3. doi:10.1016/j. bpj.2015.07.048

14. Chtcheglova LA, Hinterdorfer P. Simultaneous AFM topography and recognition imaging at the plasma membrane of mammalian cells. Semin Cell Dev Biol (2017). doi:10.1016/j.semcdb.2017.08.025

15. Ebner A, Wildling L, Kamruzzahan AS, Rankl C, Wruss J, Hahn CD, et al. A new, simple method for linking of antibodies to atomic force microscopy tips. Bioconjug Chem (2007) 18(4):1176-84. doi:10.1021/bc070030s

16. Lowndes M, Rakshit S, Shafraz O, Borghi N, Harmon R, Green K, et al. Different roles of cadherins in the assembly and structural integrity of the desmosome complex. JCell Sci (2014) 127(Pt 10):2339-50. doi:10.1242/ jcs. 146316

17. Waschke J, Bruggeman P, Baumgartner W, Zillikens D, Drenckhahn D. Pemphigus foliaceus IgG causes dissociation of desmoglein 1-containing junctions without blocking desmoglein 1 transinteraction. J Clin Invest (2005) 115(11):3157-65. doi:10.1172/JCI23475

18. Baumgartner W, Hinterdorfer P, Ness W, Raab A, Vestweber D, Schindler H, et al. Cadherin interaction probed by atomic force microscopy. Proc Natl Acad Sci U S A (2000) 97(8):4005-10. doi:10.1073/pnas.070052697

19. Priest AV, Shafraz O, Sivasankar S. Biophysical basis of cadherin mediated cellcell adhesion. Exp Cell Res (2017) 358(1):10-3. doi:10.1016/j.yexcr.2017.03.015

20. Vielmuth F, Wanuske MT, Radeva MY, Hiermaier M, Kugelmann D, Walter E, et al. Keratins regulate the adhesive properties of desmosomal cadherins through signaling. J Invest Dermatol (2018) 138(1):121-31. doi:10.1016/j. jid.2017.08.033

21. Schlegel N, Meir M, Heupel WM, Holthofer B, Leube RE, Waschke J. Desmoglein 2-mediated adhesion is required for intestinal epithelial barrier integrity. Am J Physiol Gastrointest Liver Physiol (2010) 298(5):G774-83. doi:10.1152/ajpgi.00239.2009

22. Dieding M, Debus JD, Kerkhoff R, Gaertner-Rommel A, Walhorn V, Milting H, et al. Arrhythmogenic cardiomyopathy related DSG2 mutations affect desmosomal cadherin binding kinetics. Sci Rep (2017) 7(1):13791. doi:10.1038/ s41598-017-13737-x

23. Zhou L, Cai M, Tong T, Wang H. Progress in the correlative atomic force microscopy and optical microscopy. Sensors (Basel) (2017) 17(4):E938. doi:10.3390/s17040938

24. Hauser M, Wojcik M, Kim D, Mahmoudi M, Li W, Xu K. Correlative super-resolution microscopy: new dimensions and new opportunities. Chem $\operatorname{Rev}(2017)$ 117(11):7428-56. doi:10.1021/acs.chemrev.6b00604

25. Wagner P. Immobilization strategies for biological scanning probe microscopy. FEBS Lett (1998) 430(1-2):112-5. doi:10.1016/S0014-5793(98)00614-0

26. Vielmuth F, Waschke J, Spindler V. Loss of desmoglein binding is not sufficient for keratinocyte dissociation in pemphigus. J Invest Dermatol (2015) 135(12):3068-77. doi:10.1038/jid.2015.324

27. Fung CK, Seiffert-Sinha K, Lai KW, Yang R, Panyard D, Zhang J, et al. Investigation of human keratinocyte cell adhesion using atomic force microscopy. Nanomedicine (2010) 6(1):191-200. doi:10.1016/j.nano.2009.05.008

28. Fung CK, Xi N, Yang R, Seiffert-Sinha K, Lai KW, Sinha AA. Quantitative analysis of human keratinocyte cell elasticity using atomic force microscopy (AFM). IEEE Trans Nanobioscience (2011) 10(1):9-15. doi:10.1109/ TNB.2011.2113397

29. Vielmuth F, Hartlieb E, Kugelmann D, Waschke J, Spindler V. Atomic force microscopy identifies regions of distinct desmoglein 3 adhesive properties on living keratinocytes. Nanomedicine (2015) 11(3):511-20. doi:10.1016/j. nano.2014.10.006

30. Waschke J, Spindler V. Desmosomes and extradesmosomal adhesive signaling contacts in pemphigus. Med Res Rev (2014) 34(6):1127-45. doi:10.1002/ med. 21310
31. Seiffert-Sinha K, Yang R, Fung CK, Lai KW, Patterson KC, Payne AS, et al. Nanorobotic investigation identifies novel visual, structural and functional correlates of autoimmune pathology in a blistering skin disease model. PLoS One (2014) 9(9):e106895. doi:10.1371/journal.pone.0106895

32. Muller DJ. AFM: a nanotool in membrane biology. Biochemistry (2008) 47(31):7986-98. doi:10.1021/bi800753x

33. Amagai M, Karpati S, Klaus-Kovtun V, Udey MC, Stanley JR. Extracellular domain of pemphigus vulgaris antigen (desmoglein 3 ) mediates weak homophilic adhesion. J Invest Dermatol (1994) 103(4):609-15. doi:10.1111/1523 1747.ep12397292

34. Heupel WM, Zillikens D, Drenckhahn D, Waschke J. Pemphigus vulgaris IgG directly inhibit desmoglein 3-mediated transinteraction. J Immunol (2008) 181(3):1825-34. doi:10.4049/jimmunol.181.3.1825

35. Spindler V, Heupel WM, Efthymiadis A, Schmidt E, Eming R, Rankl C, et al. Desmocollin 3-mediated binding is crucial for keratinocyte cohesion and is impaired in pemphigus. J Biol Chem (2009) 284(44):30556-64. doi:10.1074/ jbc.M109.024810

36. Waschke J, Menendez-Castro C, Bruggeman P, Koob R, Amagai M, Gruber HJ, et al. Imaging and force spectroscopy on desmoglein 1 using atomic force microscopy reveal multivalent $\mathrm{Ca}^{(2+)}$-dependent, low-affinity trans-interaction. J Membr Biol (2007) 216(2-3):83-92. doi:10.1007/s00232-0079037-9

37. Baumgartner W, Golenhofen N, Grundhofer N, Wiegand J, Drenckhahn D. $\mathrm{Ca}^{2+}$ dependency of $\mathrm{N}$-cadherin function probed by laser tweezer and atomic force microscopy. J Neurosci (2003) 23(35):11008-14.

38. Bell GI. Models for the specific adhesion of cells to cells. Science (1978) 200(4342):618-27. doi:10.1126/science.347575

39. Evans E, Ritchie K. Dynamic strength of molecular adhesion bonds. Biophys J (1997) 72(4):1541-55. doi:10.1016/S0006-3495(97)78802-7

40. Harrison OJ, Brasch J, Lasso G, Katsamba PS, Ahlsen G, Honig B, et al. Structural basis of adhesive binding by desmocollins and desmogleins. Proc Natl Acad Sci U S A (2016) 113(26):7160-5. doi:10.1073/pnas.1606272113

41. Nie Z, Merritt A, Rouhi-Parkouhi M, Tabernero L, Garrod D. Membraneimpermeable cross-linking provides evidence for homophilic, isoformspecific binding of desmosomal cadherins in epithelial cells. J Biol Chem (2011) 286(3):2143-54. doi:10.1074/jbc.M110.192245

42. Amagai M, Klaus-Kovtun V, Stanley JR. Autoantibodies against a novel epithelial cadherin in pemphigus vulgaris, a disease of cell adhesion. Cell (1991) 67(5):869-77. doi:10.1016/0092-8674(91)90360-B

43. Walter E, Vielmuth F, Rotkopf L, Sardy M, Horvath ON, Goebeler M, et al. Different signaling patterns contribute to loss of keratinocyte cohesion dependent on autoantibody profile in pemphigus. Sci Rep (2017) 7(1):3579. doi:10.1038/s41598-017-03697-7

44. Vielmuth F, Walter E, Fuchs M, Radeva M, Buechau F, Magin TM, et al. Keratins regulate p38MAPK-dependent desmoglein binding properties in pemphigus. Front Immunol (2018). doi:10.3389/fimmu.2018.00528

45. Tsunoda K, Ota T, Aoki M, Yamada T, Nagai T, Nakagawa T, et al. Induction of pemphigus phenotype by a mouse monoclonal antibody against the amino-terminal adhesive interface of desmoglein 3. JImmunol (2003) 170(4):2170-8. doi:10.4049/jimmunol.170.4.2170

46. Heupel WM, Muller T, Efthymiadis A, Schmidt E, Drenckhahn D, Waschke J. Peptides targeting the desmoglein 3 adhesive interface prevent autoantibodyinduced acantholysis in pemphigus. J Biol Chem (2009) 284(13):8589-95. doi:10.1074/jbc.M808813200

47. Payne AS, Ishii K, Kacir S, Lin C, Li H, Hanakawa Y, et al. Genetic and functional characterization of human pemphigus vulgaris monoclonal autoantibodies isolated by phage display. J Clin Invest (2005) 115(4):888-99. doi:10.1172/JCI24185

48. Spindler V, Rotzer V, Dehner C, Kempf B, Gliem M, Radeva M, et al. Peptide-mediated desmoglein 3 crosslinking prevents pemphigus vulgaris autoantibody-induced skin blistering. J Clin Invest (2013) 123(2):800-11. doi:10.1172/JCI60139

49. Tsunoda K, Ota T, Saito M, Hata T, Shimizu A, Ishiko A, et al. Pathogenic relevance of $\operatorname{IgG}$ and $\operatorname{IgM}$ antibodies against desmoglein 3 in blister formation in pemphigus vulgaris. Am J Pathol (2011) 179(2):795-806. doi:10.1016/j. ajpath.2011.04.015

50. Jennings JM, Tucker DK, Kottke MD, Saito M, Delva E, Hanakawa Y, et al. Desmosome disassembly in response to pemphigus vulgaris IgG occurs in distinct phases and can be reversed by expression of exogenous Dsg3. J Invest Dermatol (2011) 131(3):706-18. doi:10.1038/jid.2010.389 
51. Windoffer R, Beil M, Magin TM, Leube RE. Cytoskeleton in motion: the dynamics of keratin intermediate filaments in epithelia. J Cell Biol (2011) 194(5):669-78. doi:10.1083/jcb.201008095

52. Seltmann K, Fritsch AW, Kas JA, Magin TM. Keratins significantly contribute to cell stiffness and impact invasive behavior. Proc Natl Acad Sci U S A (2013) 110(46):18507-12. doi:10.1073/pnas.1310493110

53. Ramms L, Fabris G, Windoffer R, Schwarz N, Springer R, Zhou C, et al. Keratins as the main component for the mechanical integrity of keratinocytes. Proc Natl Acad Sci U S A (2013) 110(46):18513-8. doi:10.1073/pnas.1313491110

54. Broussard JA, Yang R, Huang C, Nathamgari SSP, Beese AM, Godsel LM, et al. The desmoplakin-intermediate filament linkage regulates cell mechanics. Mol Biol Cell (2017) 28(23):3156-64. doi:10.1091/mbc.E16-07-0520

55. Berkowitz P, Hu P, Liu Z, Diaz LA, Enghild JJ, Chua MP, et al. Desmosome signaling. Inhibition of p38MAPK prevents pemphigus vulgaris IgGinduced cytoskeleton reorganization. J Biol Chem (2005) 280(25):23778-84. doi:10.1074/jbc.M501365200

56. Waschke J, Spindler V, Bruggeman P, Zillikens D, Schmidt G, Drenckhahn D. Inhibition of Rho A activity causes pemphigus skin blistering. J Cell Biol (2006) 175(5):721-7. doi:10.1083/jcb.200605125

57. Gliem M, Heupel WM, Spindler V, Harms GS, Waschke J. Actin reorganization contributes to loss of cell adhesion in pemphigus vulgaris. Am J Physiol Cell Physiol (2010) 299(3):C606-13. doi:10.1152/ajpcell.00075.2010

58. Chtcheglova LA, Wildling L, Waschke J, Drenckhahn D, Hinterdorfer P. AFM functional imaging on vascular endothelial cells. J Mol Recognit (2010) 23(6):589-96. doi:10.1002/jmr.1052

59. Chtcheglova LA, Waschke J, Wildling L, Drenckhahn D, Hinterdorfer P. Nano-scale dynamic recognition imaging on vascular endothelial cells. Biophys J (2007) 93(2):L11-3. doi:10.1529/biophysj.107.109751

60. Curry N, Ghezali G, Kaminski Schierle GS, Rouach N, Kaminski CF. Correlative STED and atomic force microscopy on live astrocytes reveals plasticity of cytoskeletal structure and membrane physical properties during polarized migration. Front Cell Neurosci (2017) 11:104. doi:10.3389/fncel.2017.00104

61. Santacroce M, Orsini F, Perego C, Lenardi C, Castagna M, Mari SA, et al. Atomic force microscopy imaging of actin cortical cytoskeleton of Xenopus laevis oocyte.J Microsc(2006)223(Pt1):57-65.doi:10.1111/j.1365-2818.2006.01596.x

62. Usukura E, Suzuki T, Furuike S, Soga N, Saita E, Hisabori T, et al. Torque generation and utilization in motor enzyme F0F1-ATP synthase: half-torque F1 with short-sized pushrod helix and reduced ATP synthesis by half-torque F0F1. J Biol Chem (2012) 287(3):1884-91. doi:10.1074/jbc.M111.305938

63. Quinlan RA, Schwarz N, Windoffer R, Richardson C, Hawkins T, Broussard JA, et al. A rim-and-spoke hypothesis to explain the biomechanical roles for cytoplasmic intermediate filament networks. J Cell Sci (2017) 130(20):3437-45. doi:10.1242/jcs.202168

64. Waschke J. The desmosome and pemphigus. Histochem Cell Biol (2008) 130(1):21-54. doi:10.1007/s00418-008-0420-0

65. Denning MF, Guy SG, Ellerbroek SM, Norvell SM, Kowalczyk AP, Green KJ. The expression of desmoglein isoforms in cultured human keratinocytes is regulated by calcium, serum, and protein kinase C. Exp Cell Res (1998) 239(1):50-9. doi:10.1006/excr.1997.3890

66. Rotzer V, Hartlieb E, Vielmuth F, Gliem M, Spindler V, Waschke J. E-cadherin and Src associate with extradesmosomal Dsg3 and modulate desmosome assembly and adhesion. Cell Mol Life Sci (2015) 72(24):4885-97. doi:10.1007/ s00018-015-1977-0

67. Tsang SM, Brown L, Lin K, Liu L, Piper K, O’Toole EA, et al. Non-junctional human desmoglein 3 acts as an upstream regulator of Src in E-cadherin adhesion, a pathway possibly involved in the pathogenesis of pemphigus vulgaris. J Pathol (2012) 227(1):81-93. doi:10.1002/path.3982

68. Oktarina DA, van der Wier G, Diercks GF, Jonkman MF, Pas HH. IgG-induced clustering of desmogleins 1 and 3 in skin of patients with pemphigus fits with the desmoglein nonassembly depletion hypothesis. Br JDermatol (2011) 165(3):552-62. doi:10.1111/j.1365-2133.2011.10463.x

69. Yoshida K, Ishii K, Shimizu A, Yokouchi M, Amagai M, Shiraishi K, et al. Non-pathogenic pemphigus foliaceus (PF) IgG acts synergistically with a directly pathogenic PF IgG to increase blistering by p38MAPK-dependent desmoglein 1 clustering. J Dermatol Sci (2017) 85(3):197-207. doi:10.1016/j. jdermsci.2016.12.010

70. Stahley SN, Warren MF, Feldman RJ, Swerlick RA, Mattheyses AL, Kowalczyk AP. Super-resolution microscopy reveals altered desmosomal protein organization in tissue from patients with pemphigus vulgaris. J Invest Dermatol (2016) 136(1):59-66. doi:10.1038/JID.2015.353

71. Rotzer V, Hartlieb E, Winkler J, Walter E, Schlipp A, Sardy M, et al. Desmoglein 3 -dependent signaling regulates keratinocyte migration and wound healing. J Invest Dermatol (2016) 136(1):301-10. doi:10.1038/jid.2015.380

72. Berkowitz P, Hu P, Warren S, Liu Z, Diaz LA, Rubenstein DS. p38MAPK inhibition prevents disease in pemphigus vulgaris mice. Proc Natl Acad Sci U S A (2006) 103(34):12855-60. doi:10.1073/pnas.0602973103

73. Berkowitz P, Diaz LA, Hall RP, Rubenstein DS. Induction of p38MAPK and HSP27 phosphorylation in pemphigus patient skin. J Invest Dermatol (2008) 128(3):738-40. doi:10.1038/sj.jid.5701080

Conflict of Interest Statement: The authors declare that the research was conducted in the absence of any commercial or financial relationships that could be construed as a potential conflict of interest.

The reviewer PK and handling Editor declared their shared affiliation.

Copyright (c) 2018 Vielmuth, Spindler and Waschke. This is an open-access article distributed under the terms of the Creative Commons Attribution License (CC BY). The use, distribution or reproduction in other forums is permitted, provided the original author(s) and the copyright owner are credited and that the original publication in this journal is cited, in accordance with accepted academic practice. No use, distribution or reproduction is permitted which does not comply with these terms. 